\title{
Correction to: Modelling whole heart electrical activity for ischemia and cardiac pacing simulation
}

\author{
Niccoló Biasi ${ }^{1,2} \cdot$ Alessandro Tognetti ${ }^{1,3}$
}

Published online: 25 May 2020

(C) IUPESM and Springer-Verlag GmbH Germany, part of Springer Nature 2020

\section{Correction to: Health and Technology}

https://doi.org/10.1007/s12553-020-00417-6

This original article contained a mistake.

Fig. 6, about the 12 standard ECG leads in healthy condition, reported a copy of Fig. 11 (12 standard ECG leads in posterior ischemia condition). We modified Fig. 6 reporting the correct results on the ECG in healthy condition.

The original article has been corrected.

The online version of the original article can be found at https://doi.org/ 10.1007/s12553-020-00417-6

\footnotetext{
Niccoló Biasi

biasi.niccolo96@gmail.com

Alessandro Tognetti

alessandro.tognetti@unipi.it

1 Dipartimento di Ingegneria dell'Informazione, Universitá di Pisa, Pisa, Italy

2 Universitá di Pisa, Pisa, Italy

3 Centro E. Piaggio, Universitá di Pisa, Pisa, Italy
} 

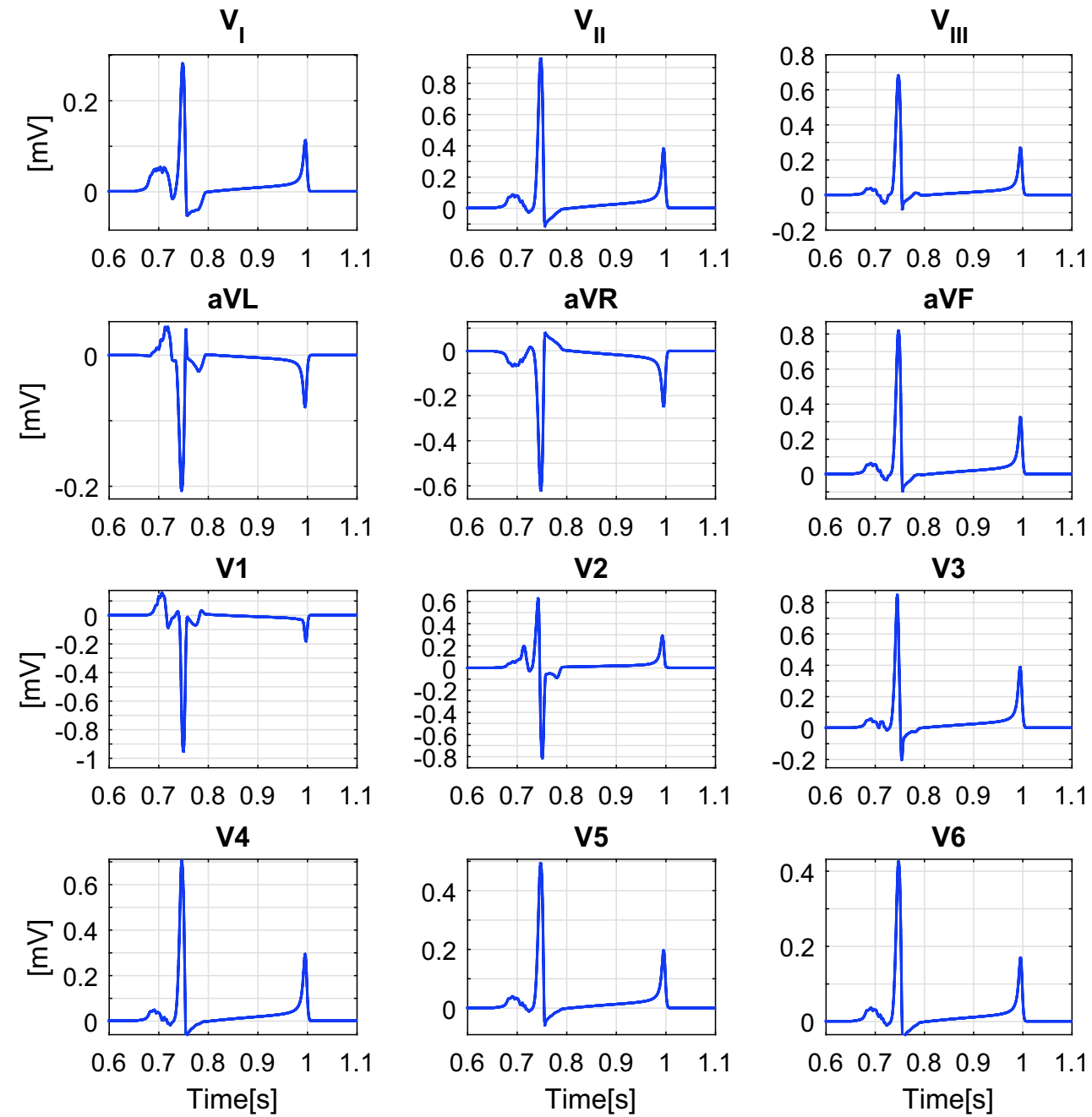

Fig. 6 Healthy 12 standard leads ECG

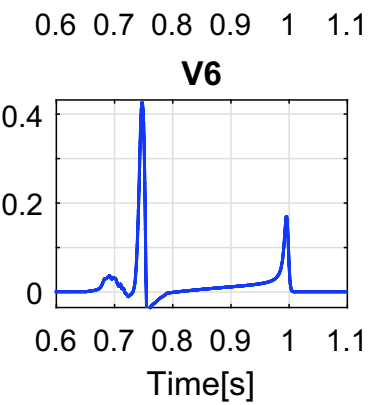

